\title{
Does landscape context mediate the nature of density dependence for a coral reef fish?
}

\author{
Lauren A. Yeager,${ }^{1,2,4}$ Elizabeth W. Stoner, ${ }^{1}$ Martha J. Zapata, ${ }^{1}$ and Craig A. Layman ${ }^{1,3}$ \\ ${ }^{1}$ Florida International University, Marine Science Program, Department of Biological Sciences, 3000 NE 151st Street, North Miami, \\ Florida 33181 USA \\ ${ }^{2}$ University of North Carolina at Chapel Hill, Institute of Marine Sciences, Morehead City, North Carolina 28557 USA \\ ${ }^{3}$ Department of Applied Ecology, North Carolina State University, Raleigh, North Carolina 27695-7105 USA
}

\begin{abstract}
Over-harvest and landscape change are two of the greatest threats to marine ecosystems. Over-harvest may directly affect key population regulation mechanisms (e.g., density dependence), with the magnitude of the effects being further influenced by changes in landscape structure and associated resource availability. Because resource availability and conspecific density often co-vary within the natural landscape, manipulative experiments are needed to understand how changes in these two drivers may affect density dependence in wild populations. We used a common, shoaling, coral reef fish (white grunt, Haemulon plumierii) as our model species, and manipulated fish densities and landscape context of artificial reef habitats to assess the effects of each on fish condition. We found evidence of inverse density dependence, where individual condition was positively related to conspecific density; landscape context had little effect. Mean grunt condition on natural patch reefs was similar to that for our low grunt density treatment artificial reefs, possibly due to differences in fish densities or landscape context. These findings suggest that over-harvest may have detrimental effects on wild populations that extend beyond mere reductions in population size, especially for group-living species.
\end{abstract}

Key words: artificial reef; competition; condition; food web; group behavior; Haemulon plumierii; seagrass.

\section{INTRODUCTION}

Long-term persistence of wild populations is a primary goal of resource managers. Populations that are regulated by density-dependent factors, by definition, should display enhanced persistence and stability, as negative feedbacks tend to constrain extreme population fluctuations (Hanski 1990, Murdoch 1994, Hixon et al. 2002). Populations of reduced size due to over-harvest may display weakened density-dependent regulation and enhanced susceptibility to environmental fluctuations (Anderson et al. 2008), resulting in heightened risk of extirpation or extinction. Population models of harvested species assume that compensatory density dependence, or increased population growth rates, should occur when population densities are reduced below carrying capacity (Rose et al. 2001). Specifically, increased reproduction, survival, individual condition, or somatic growth due to decreased competition, should offset some of the losses resulting from harvest. For example, a study by Lorenzen and Enberg (2002) found compensatory increases in individual growth rates in response to low biomass of conspecifics in populations of nine out of 16 fisheries species.

Manuscript received 4 December 2013; revised 17 March 2014; accepted 18 March 2014. Corresponding Editor: P. K. Dayton.

${ }^{4}$ E-mail: laurenayeager@gmail.com
Landscape context has the potential to alter multiple biological factors, which may affect competition and the strength of density-dependent interactions. For instance, landscape characteristics such as patch size, edge: interior ratios, and structural complexity may affect shelter availability or predator encounter rates, impacting predator-prey dynamics for focal species (Power 1992, Irlandi et al. 1995, Hovel and Lipcius 2001, Chalfoun et al. 2002). Similarly, habitat heterogeneity within the landscape may lead to increased availability of food, diversity of food resources, and trophic flow across habitat boundaries, which may affect the degree of competition among conspecifics (Polis et al. 1997, Vickery et al. 2001). For example, Persson (1983) suggested that habitat heterogeneity reduced between-age-class competition for prey resources in perch (Perca fluvaitilis) in Swedish lakes and may promote faster growth rates and age-class diversity for this species.

In natural systems, however, variation in resource availability within the surrounding landscape often leads to concomitant variation in conspecific abundance, two factors that have opposing effects on competition. If the distribution of individuals matched resource availability across the landscape, there should be no difference in the strength of competition among patches of varying densities (Fretwell and Lucas 1970). However, there is often a spatial and/or temporal mismatch between the distribution of resources and individuals, which may 


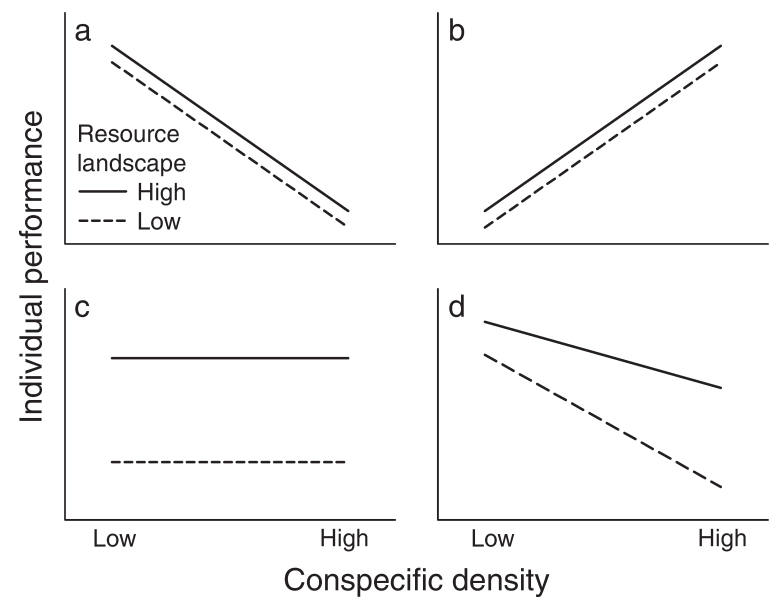

FIG. 1. Conceptual model of possible relationships between landscape context (high vs. low resource availability), conspecific density (low vs. high), and individual performance measures. Possible scenarios include (a) individual performance shows direct density dependence with the response independent of landscape context, (b) inverse density-dependent response of performance independent of landscape context, (c) performance is density-independent, but varies with landscape context, (d) performance is density-dependent, but is mediated by landscape context.

lead to differences in the strength of density-dependent interactions (Wang et al. 2006, Finstad et al. 2009, Teichert et al. 2013). This covariation makes it difficult to discern the overall effect of landscape context on density-dependent competition from field surveys alone. Experimental manipulations are needed to understand the link between landscape context and density dependence, and improve our understanding of how a combination of stressors, such as over-harvest and habitat degradation, may affect regulation of wild populations.

The relationship between conspecific density and resource availability is more complex in group-living species. This is because individuals must trade-off the costs (e.g., increased competition for resources, increased risk of disease) with the benefits (e.g., increased predator vigilance) of associations with higher densities of conspecifics (Pulliam and Caraco 1984). When considering foraging, living in larger groups may result in local resource depletion from increased competition, causing a density-dependent decline in growth or condition (Okamura 1986, White and Warner 2007). Conversely, groups may be better at locating resource patches (Pitcher et al. 1982), or time spent foraging may increase due to lower predation risk (Caraco et al. 1980). As such, the relationship among landscape context, resource availability, and density dependence may be fundamentally different for group-living species than solitary species.

We present four scenarios related to the effects of landscape context and conspecific density on individual performance (e.g., growth, condition, survival, etc.) for a group-living species (other scenarios and outcomes are also possible). If competition for resources is the most important factor affecting individual performance and is strong compared to weak effects of resource availability, performance should decrease as conspecific densities increase (e.g., direct density dependence), largely independent of landscape context (Fig. 1a). If there is a benefit to group living, which is again stronger than effects of resource availability in the landscape, individual performance should increase with conspecific density (e.g., inverse density dependence), independent of landscape context (Fig. 1b). Conversely, if resource availability is the most important factor driving individual performance and costs or benefits of group living are relatively weak (e.g., density independence), measures of performance should be highest in high resource landscapes and be independent of conspecific density (Fig. 1c). Finally, if higher resource availability within the landscape offsets some of the competitive effects of increases in conspecific density or further enhances the benefits of group living, we would expect to see an interaction between landscape context and conspecific density (Fig. 1d).

Our objective was to determine if variation in landscape context has the potential to mediate the relationship between conspecific density and a metric of individual performance (i.e., condition) for a groupliving species of coral reef fish. We used artificial reefs as model habitat patches and manipulated the landscape context in which they were created, as well as manipulated conspecific densities on the reefs, to address this objective. Additionally, we compared condition of grunts on artificial reefs to that of grunts from natural patch reefs in the study area. By taking a novel approach in simultaneously manipulating landscape context and fish densities, we hope to provide insight into how two important anthropogenic stressors (i.e., habitat alteration and overharvest) could affect population regulation of marine fisheries.

\section{Methods \\ Study site}

Artificial reefs were created in the Sea of Abaco, Abaco Island, Bahamas (Fig. 2). The surrounding landscape ranges from 2 to $3 \mathrm{~m}$ deep and includes soft-bottom habitat dominated by Thalassia testudium seagrass beds and a number of natural patch reefs ranging in size from individual coral heads to $\sim 500 \mathrm{~m}^{2}$. In May 2011, artificial reefs were constructed from 30 concrete blocks (block size $15 \times 20 \times 40 \mathrm{~cm}$ ) arranged in a cuboid shape (Fig. 3a). Blocks were secured together underwater using polypropylene rope. Seagrass cover was estimated visually by surveying $1-\mathrm{m}^{2}$ quadrats within the landscape. One quadrat was placed directly at the site designated for reef creation and $100-\mathrm{m}$ transects $(N=5)$ were run pentaradially out from the reef site, on which a quadrat was placed every $25 \mathrm{~m}(N=$ 21 points per reef). Seagrass cover estimates were made 


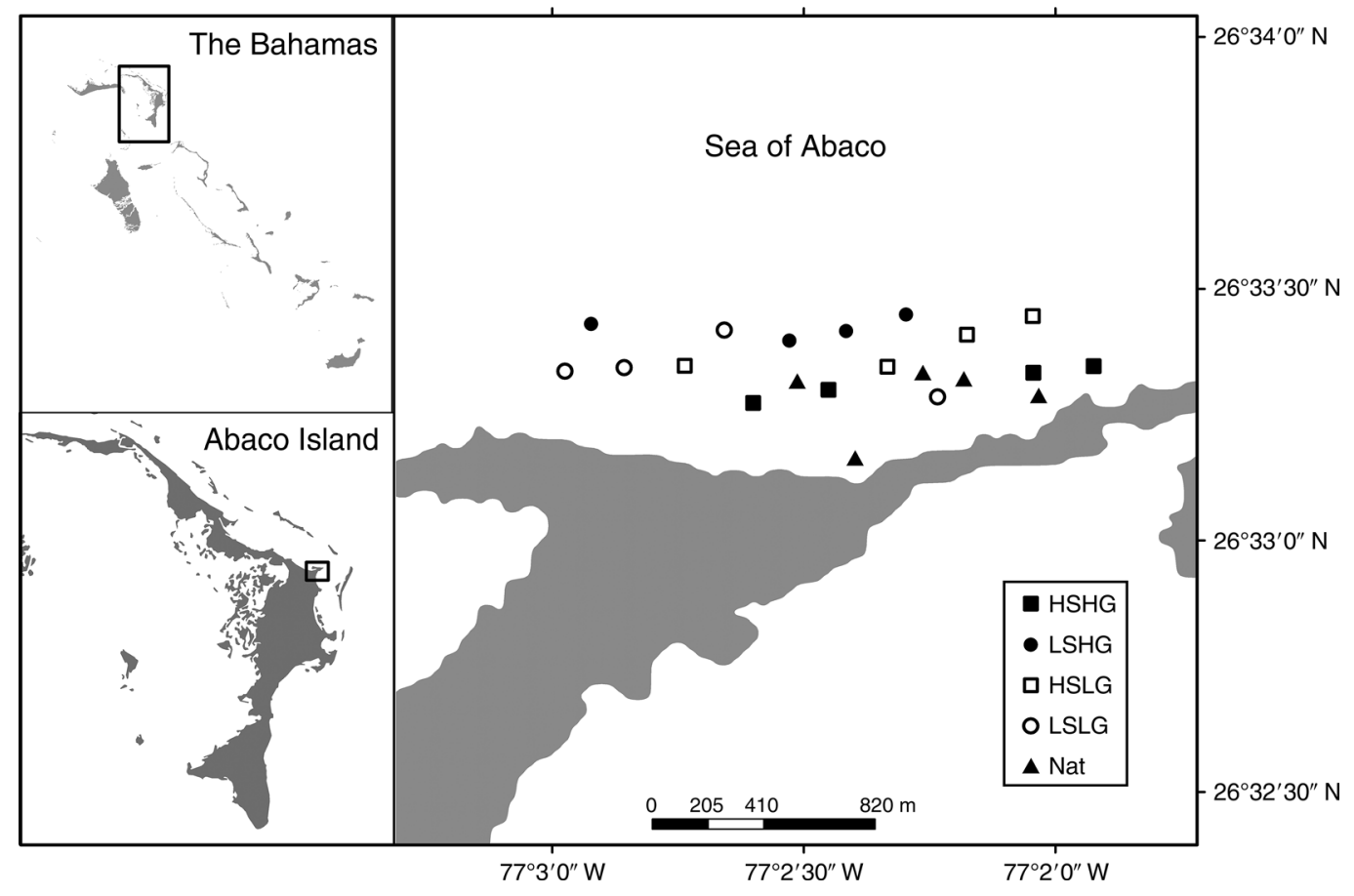

FIG. 2. Map of the study area with locations of artificial and natural reef sites on Abaco Island, Bahamas. Abbreviations are HSHG, high seagrass cover, high grunt density; LSHG, low seagrass cover, high grunt density; HSLG, high seagrass cover, low grunt density; and LSLG, low seagrass cover, low grunt density treatment artificial reefs, Nat stands for natural patch reefs.

before reef creation to designate high (HS) and low seagrass cover (LS) sites. Eight reefs were created in HS landscapes (range in mean seagrass cover across reefs $=$ $49-76 \%$, mean $\pm \mathrm{SE}=58.2 \% \pm 3.2 \%$ ) and eight in $\mathrm{LS}$ landscapes (range $=29-42 \%$, mean $\pm \mathrm{SE}=36.5 \% \pm$ $2.4 \%$ ). Reefs were created at least $80 \mathrm{~m}$ from any hardbottom habitat and $200 \mathrm{~m}$ from other artificial reefs.

Five natural patch reefs were selected for comparison with artificial reefs (Fig. 3b). Natural reefs were isolated from each other by at least $70 \mathrm{~m}$ and isolated from artificial reefs by at least $80 \mathrm{~m}$. Patch reef size was estimated by two snorkelers, assuming an approximate ellipsoid shape for the reefs and measuring the major and minor axes with an underwater transect tape to the nearest $\mathrm{m}$. These reefs ranged in size from 56 to $420 \mathrm{~m}^{2}$ (Table 1). Seagrass cover around natural patch reefs was surveyed along five $100 \mathrm{~m}$ transects radiating out from the reef ( $N=20$ quadrats per reef) similar to the approach described for artificial reefs.

\section{Study species}

Grunts (Haemulidae) are a ubiquitous family of coral reef fishes and represent an important fisheries resource in the greater Caribbean region (Randall 1963, Appeldoorn and Lindeman 1985, Grober-Dunsmore et al. 2008). Juvenile white grunts (Haemulon plumierii) are known to make nightly foraging movements from their daytime reef resting sites to surrounding soft-bottom habitats to feed (Ogden and Ehrlich 1977, Helfman et al. 1982). During these nightly foraging bouts, they travel between tens to hundreds of meters to reach soft-bottom habitats where they feed on benthic invertebrates (Ogden and Ehrlich 1977, Appeldoorn et al. 2009). Time-lapse photography surveys of the same array of natural and artificial reefs confirm that grunts leave the reefs at night, presumably to forage (Zapata 2013). Juveniles are known to exhibit high site fidelity to resting habitats, using the same coral head for days to months (Helfman et al. 1982, McFarland and Hillis 1982). Their nightly foraging migration routes are also known to be stable over time, as the same individuals have been observed following the same foraging routes for months (Ogden and Ehrlich 1977). Juvenile white grunts are primarily benthic invertivores and have been observed to feed nocturnally in seagrass (as opposed to unvegetated bottom [Ogden and Zieman 1977, Appeldoorn et al. 1997]) and benthic invertebrate densities have been shown to increase with seagrass cover in our system (Yeager et al. 2012). This foraging pattern represents important food web and nutrient subsidies linking reef and seagrass habitats (Meyer et al. 1983, Clark et al. 2009, Allgeier et al. 2013).

\section{Data collection}

White grunts were allowed to colonize reefs from May to October 2011. In our system, most grunts (1-2 cm total length) recruit to reef habitats during late spring/ summer months (May to July) and little recruitment occurs during the fall or winter (L. A. Yeager, unpublished data). Half of the reefs in each landscape 

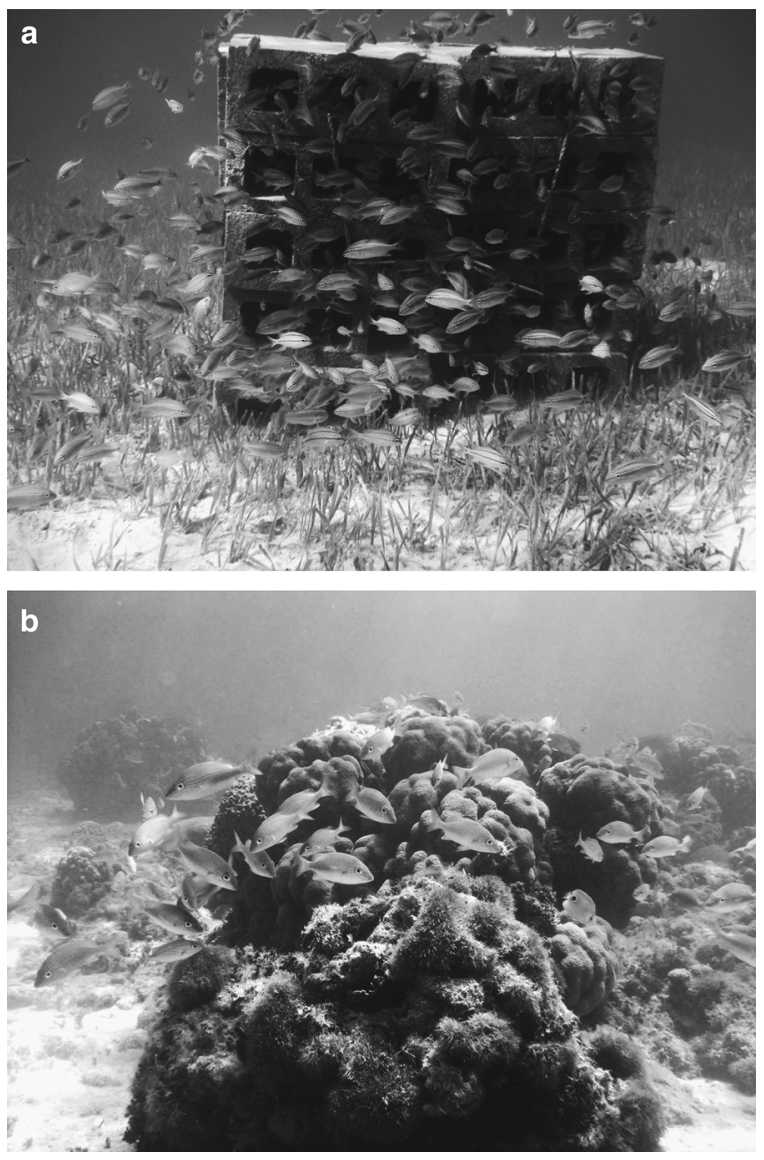

FIG. 3. Photographs of (a) a high seagrass cover, high grunt density artificial reef and (b) a natural patch reef; note the sand/ halo carbonate bank surrounding the natural reef. Almost all of the fishes visible are white grunts (Haemulon plumierii).

type were randomly assigned to high (HG) and low grunt density (LG) treatments. Attempts to add juvenile grunts to artificial reefs failed (grunts would return to home reefs within 48 hours of translocation, as far as 1 $\mathrm{km}$ away); therefore, removals were used to manipulate densities. During October and November of 2011, targeted grunt removals using unbaited fish traps were used on the LG treatment reefs to reduce fish densities to $<50$ individuals/reef. Densities (mean $\pm \mathrm{SE}$ ) on unmanipulated (HG treatment) reefs in November 2011 were $134.5 \pm 26.1$ grunts/reef.
To ensure that grunts were not moving between reefs, we tagged a subset of grunts using visible implant elastomer tags (Northwest Marine Technology, Shaw Island, Washington, USA). In June 2012, white grunts from each reef were tagged with a unique color combination under the skin on the caudal peduncle. A total of 262 grunts across the 16 artificial reefs were tagged with elastomer dye, representing $\sim 50 \%$ of all grunts on reefs. The presence of tagged grunts on reefs was monitored for one month using trapping and visual surveys.

In July 2012, eight months after grunt removals, grunt abundances were surveyed using a roving diver technique (Schmitt et al. 2002) on artificial reefs, as well as five natural reefs, on two dates. We used mean white grunt abundance/reef as our estimate of conspecific density. Since reef size did not vary among artificial reefs, counts of white grunts across reefs are directly comparable. However, natural reefs were much larger in size and comparisons of grunt abundance per reef vs. density per unit reef area varied greatly. Although areabased estimates of grunt density were much lower for natural reefs (Table 1), grunts often occupy only a small subset of available shelter on natural reefs (often limited to select coral heads [McFarland and Hillis 1982]), and estimates of density across the whole reef likely obscure higher densities at finer scales. Moreover, while it is possible that increased competition for shelter affected white grunt condition in our study, quantity of and access to food resources within the landscape seems a more likely driver of differences in condition for juvenile white grunts. As such, we suggest that comparisons between natural and artificial reefs based on the number of individuals per reef, as opposed to density per unit reef area, are the most meaningful.

Grunts were collected from reefs from 14 to 27 July 2012 using unbaited fish traps. We only collected grunts larger than $5 \mathrm{~cm}$ (fish standard length $=92 \pm 1.5 \mathrm{~mm}$ [ mean $\pm \mathrm{SE}]$ ), i.e., grunts that had recruited the previous year. Grunts that recruited during 2012 were generally $<4 \mathrm{~cm}$, at which size they are primarily planktivorous and would not be competing with larger juveniles for food resources (Helfman et al. 1982).

We used lipid content as a proxy of individual condition. Higher lipid stores are known to be associated with increased survival probabilities and faster

TABLE 1. Characteristics of artificial and natural reefs used in this study.

\begin{tabular}{lccccr}
\hline \hline Reef type & $\begin{array}{c}\text { No. } \\
\text { replicates }\end{array}$ & $\begin{array}{c}\text { Reef area } \\
\left(\mathrm{m}^{2}\right)\end{array}$ & $\begin{array}{c}\text { Cover of seagrass } \\
\text { within } 100 \mathrm{~m}(\%)\end{array}$ & $\begin{array}{c}\text { White grunt abundance } \\
\text { (no. fish/reef) }\end{array}$ & $\begin{array}{c}\text { White grunt density } \\
(\text { no. fish/m }\end{array}$ \\
\hline HSHG & 4 & 0.48 & $54 \pm 1$ & $111.4 \pm 25.2$ & $232.1 \pm 52.5$ \\
LSHG & 4 & 0.48 & $38 \pm 4$ & $54.5 \pm 23.5$ & $113.5 \pm 49.0$ \\
HSLG & 4 & 0.48 & $62 \pm 6$ & $24.2 \pm 7.6$ & $50.4 \pm 15.8$ \\
LSLG & 4 & 0.48 & $35 \pm 3$ & $16.9 \pm 9.3$ & $35.2 \pm 19.4$ \\
Natural patch reef & 5 & $246 \pm 58$ & $55 \pm 13$ & $161.5 \pm 32.5$ & $2.2 \pm 0.1$
\end{tabular}

Notes: Values represent mean $\pm \mathrm{SE}$ for each group. Note that all artificial reefs were created to be the same size. Abbreviations are HSHG, high seagrass cover, high grunt density; LSHG, low seagrass cover, high grunt density; HSLG, high seagrass cover, low grunt density; and LSLG, low seagrass cover, low grunt density treatment artificial reefs. 
growth rates in juvenile fish (Post and Parkinson 2001, Johnson 2008). A subset of grunts $(N=10 \mathrm{fish} /$ reef $)$ were processed for lipid content in the laboratory at Florida International University. Lipid content analysis was performed on a $100-\mathrm{mg}$ subsample of homogenized, whole fish, after stomach contents were removed, following the Bligh and Dryer (1959) method modified for use with the less toxic dichloromethane:methanol solvent in place of chloroform:methanol (Erickson 1993).

\section{Data analysis}

We used our white grunt tagging/recapture data to opportunistically assess bias associated with using fish traps as a method to capture and remove white grunts. If certain phenotypes (e.g., fish of a smaller body size) were more likely to enter traps, this could have been problematic as we used traps to remove a subset of individuals for the LG reefs at the start of the experiment and could have introduced an unintended bias into our experimental treatments. We used a paired $t$ test to compare the proportion of fish captured in traps that were tagged during our resurveys of the reefs (representing recaptures) to the proportion of all fish on the reef that were tagged. If the proportion of fish caught in traps that represented recaptures was greater than the proportion of total fish tagged on a given reef, this may indicate a selection bias associated with trapping, where certain individuals are more likely to enter traps than others.

Next, we compared fish lipid content across reefs to determine if condition varied. To ensure that ontogenetic effects were not driving differences in lipid content among individuals, we used a linear regression to test for effects of fish size (standard length) on lipid content across all reefs. To evaluate how condition varied among our treatments, we used a two-way ANOVA to assess effects of landscape type (HS vs. LS) and conspecific densities (HG vs. LG) on mean lipid content of white grunts on artificial reefs. One HSLG reef was excluded because only one grunt could be recaptured at the end of the experiment. Additionally, because there was variation in fish density and seagrass cover within our designated treatments (Table 1), we also regressed mean lipid content on seagrass cover and mean conspecific density (log-transformed to improve normality) using a general linear model. We used partial regression plots to isolate the effects of each of our independent variables on mean lipid content and we report $\eta^{2}$ (a measure of the amount of unique variation explained by each independent variable) as a metric of effect size.

Since we did not find strong effects of landscape context (see Results) on mean lipid content of grunts on artificial reefs, we compared lipid content for grunts on HG and LG artificial reefs to lipid content for grunts collected on natural reefs using a one-way ANOVA. We used a similar ANOVA to test for differences in fish size

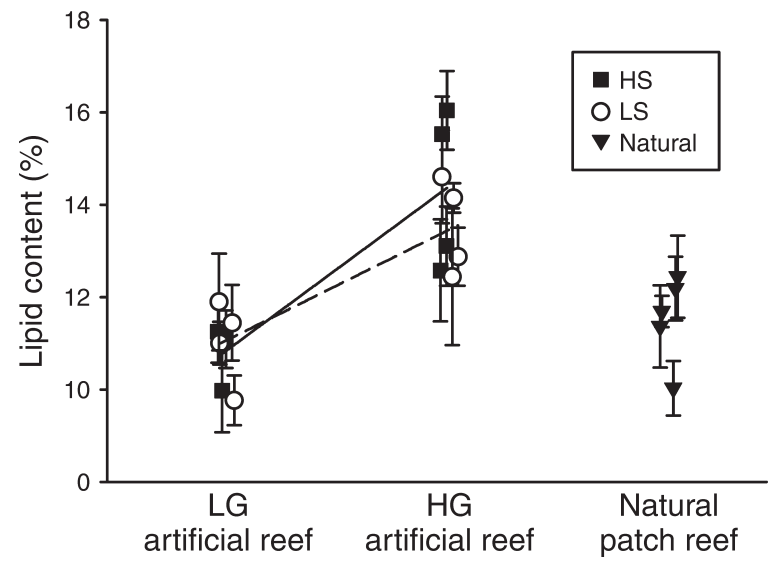

FIG. 4. Grunt lipid content (mean $\pm \mathrm{SE}$ ) for artificial reefs with varying grunt densities (HG [high grunt density treatment] vs. LG [low grunt density treatment]) within high seagrass cover (HS; squares) and low seagrass cover (LS; circles) landscapes. Grunt lipid content for natural patch reefs (triangles) is included for comparison. Solid line shows density-dependent relationship for HS and dashed line for LS reefs.

(standard length) for fish analyzed for lipid content among reefs to ensure any differences among reef types were not due to differences in body size. All tests were performed in SAS software version 9.3 (SAS Institute 2012).

\section{RESULTS}

White grunt densities declined throughout the experiment, but remained elevated on $\mathrm{HG}$ treatment reefs. The mean grunt density, averaged between surveys conducted immediately after removals and at the end of the experiment, was approximately four times higher on the $\mathrm{HG}$ artificial reefs $(78 \pm 16$ fish/reef $[$ mean $\pm \mathrm{SE}])$ compared to the LG reefs $(20 \pm 3$ fish/reef $)$. Grunt densities for the HG treatment were greater for HS reefs than LS reefs (Table 1).

Based on four to five surveys per reef, 98 tagged grunts were resighted/recaptured, with some individuals potentially sighted on more than one date. All of the resights were grunts on their original reef, and none were observed on a reef other than the one on which they were tagged. Additionally, the proportion of grunts representing recaptures in traps $(26 \% \pm 5 \%$ of fish were tagged) was lower than the proportion of fish tagged on a given reef $(49 \% \pm 4 \%$ of fish tagged on a reef, $t=-3.6$, $P<0.001)$. Since fish that were tagged were originally caught using fish traps, this may indicate a reticence by grunts to reenter traps and/or differential mortality of tagged and untagged grunts. However, these data do not support a positive selection bias for certain individuals/ phenotypes, which may have resulted in unintended selection for certain individuals during fish removals.

There was no relationship between lipid content and fish size $\left(F_{1,133}=2.4, P=0.1\right)$. For artificial reefs, mean lipid content was higher for grunts on the HG reefs $\left(F_{1,14}=23.8, P=0.0004\right.$, Fig. 4$)$. There was no effect of 

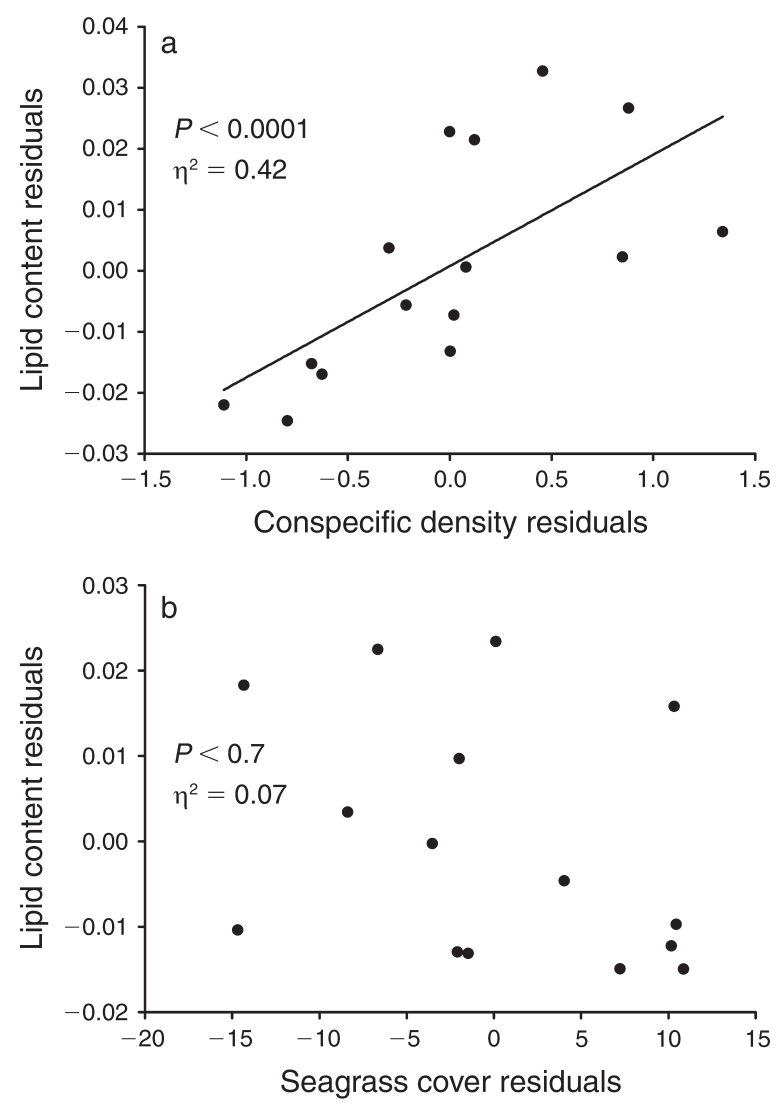

FIG. 5. Partial regression plots illustrating the effects of mean conspecific density (log-transformed; measured as number of fish per reef) and seagrass cover within the landscape $(100 \mathrm{~m})$ on mean lipid content (percent) for white grunts on artificial reefs. Axis values represent residuals and each point represents a reef. The parameter $\eta^{2}$ is the amount of unique variation in the response variable explained by each predictor variable.

landscape context (HS vs. LS) on mean grunt lipid content $\left(F_{1,14}=0.3, P=0.6\right)$. These results were consistent with the scenario depicted in Fig. $1 \mathrm{~b}$ (inverse density dependence, independent of landscape context). Similar results were found by treating mean conspecific density and seagrass cover as continuous variables (Fig. 5). There was a positive effect of mean conspecific density (log-transformed) on mean lipid content for grunts on artificial reefs (amount of unique variation in the response variable explained by the predictor variable $\left.\left(\eta^{2}\right)=0.42, F_{1,14}=46.1, P<0.0001\right)$. There was no effect of seagrass cover within the landscape on mean lipid content $\left(\eta^{2}=0.07, F_{1,14}=0.2, P=0.7\right)$.

Grunt abundances on natural patch reefs were nearly twice as great as the abundances on HG artificial reefs $(161.5 \pm 32.5 \mathrm{fish} / \mathrm{reef})$, although densities based on reef area were much lower (Table 1; see Discussion for more on comparisons based on abundance vs. density). Seagrass cover within the landscape around natural reefs $(55.4 \% \pm 2.7 \%)$ was similar to that for HS artificial reefs (Table 1). However, the natural patch reefs were surrounded by a carbonate bank and estimates of mean seagrass cover within $25 \mathrm{~m}$ of the natural reefs were much lower than those surrounding artificial reefs $(23.8 \% \pm 14.1 \%$ vs. $50.7 \% \pm 4.3 \%$, respectively). There was a difference in mean grunt lipid content among artificial reefs with varying fish densities (HG vs. LG) and natural patch reefs $\left(F_{2,19}=15.4, P=0.0002\right.$, Fig. 4). Post-hoc comparisons revealed mean lipid content for grunts on natural reefs was significantly lower than that for grunts on the $\mathrm{HG}$ artificial reefs $(P=0.004)$, but was similar to that for grunts on the LG artificial reefs $(P=$ $0.6)$. There was no difference in white grunt size among artificial reefs with varying fish densities (HG vs. LG) and natural patch reefs $\left(F_{2,18}=1.4, P=0.3\right)$.

\section{DisCUSSION}

We found a positive relationship between conspecific densities and a metric of individual performance (i.e., condition) for white grunts on artificial reefs, suggesting there is a benefit to larger aggregation sizes. This indicates that lowering conspecific densities through over-harvest could actually reduce performance for remaining individuals, instead of the common expectation of increasing performance by releasing them from competition. Like white grunts, many other Caribbean reef species that are targets of fishing pressure (e.g., snapper, Lutjanidae) also school/shoal and may display a similar response to variation in conspecific density (Wormald et al. 2012). Variation in landscape context did not seem to affect the nature of the densitydependent response in white grunt condition. However, lower condition of grunts on natural patch reefs (where grunt abundances were greater) suggests that there may be nonlinear effects of conspecific densities, or that landscape differences between natural and artificial reefs alter the relationship between conspecific density and grunt condition.

While simple competition models may predict that mean individual condition should be inversely related to conspecific density, this is not always the case for groupliving species. One advantage to aggregating behavior is increased predator vigilance, and being associated with larger groups of conspecifics may allow these groups to forage in riskier areas. For example, Magurran and Pitcher (1983) demonstrated that the number of visits to, and time spent at, an unsheltered foraging patch increased with group size for goldfish and minnows. We noticed a similar behavior with grunts; on reefs with higher fish densities, groups would migrate out from the reef up to $10 \mathrm{~m}$ during the day to make opportunistic foraging forays in surrounding seagrass (L. A. Yeager, personal observation). This behavior was not observed for grunts on LG reefs, where small group sizes may correspond to higher predation risk when leaving the reef during the day. Therefore, large group sizes may lead to enhanced individual performance through increased foraging opportunities. 
Interestingly, white grunts on natural patch reefs displayed lower mean condition levels than the white grunts on the HG artificial reefs, even though conspecific group sizes were largest on natural reefs. These differences may be due to non-linear effects of group size, differences in landscape context between the natural and artificial reefs, or bias in estimating fish abundance/density due to issues of scale when comparing natural and artificial reefs. First, it is possible that the larger group sizes of grunts on natural reefs passed some threshold beyond which increased competition for resources outweighed benefits of increasing conspecific density (Pulliam and Caraco 1984). Nightly foraging migrations in grunts involve collective departure at twilight, and the larger group subsequently disperses in a dendritic pattern until solitary individuals are left to forage over a small area until returning to the reef before dawn (Ogden and Ehrlich 1977, Helfman et al. 1982, Burke 1995). Therefore, larger group sizes may result in individuals dispersing over larger areas each night in order to reach solitary foraging patches, increasing the energetic cost associated with these migrations.

Alternatively, the landscape configuration surrounding natural patch reefs could be driving differences in the frequency of feeding or distance traveled to feed, reducing some of the positive benefit of larger group sizes on these reefs. Mean seagrass cover within $25 \mathrm{~m}$ surrounding the reef was lower for natural reefs than for artificial reefs, potentially resulting in lower resource availability within the adjacent landscape and forcing grunts to migrate longer distances at night to feed. Furthermore, natural patch reefs in this area were often surrounded by a large carbonate bank, separating the reef structure from soft bottom habitats by up to $15 \mathrm{~m}$. Therefore, grunts on natural patch reefs may not cross this larger carbonate bank during the day to forage diurnally due to the increased associated predation risk, even if group sizes were larger. Higher predator densities on natural patch reefs (L. A. Yeager, unpublished data) could further reduce the willingness of grunts to make any movements away from the reef structure during the day. Previous studies on grunt behavior on natural patch reefs in the Virgin Islands have similarly reported a lack of foraging activity during the day (Ogden and Ehrlich 1977, Helfman et al. 1982). However, landscape context of natural reefs varies, and such a large bank or halo is not always present. Therefore, opportunistic, diurnal foraging may occur in other systems, as has been observed for French grunts (Haemulon flavolineatum; Verweij et al. 2006).

Third, differences between natural and artificial reefs may be due to the way in which we surveyed conspecific abundance (as individuals per reef). While group sizes of grunts on natural patch reefs were larger than those on artificial reefs, density per unit area of resting habitat were much lower owing to larger reefs sizes. Therefore, if grunts receive a benefit from living in higher density groups, lower abundance per unit area on daytime resting habitat could also explain lower condition on natural reefs. While many reef fish species are known to be limited by shelter availability (Hixon and Beets 1993), white grunt densities on natural reefs in our system were relatively low and shelter availability on natural reefs was much higher than that on artificial reefs. Therefore, we suggest that variation in condition among reef types is more likely a result of differential access to foraging resources than competition for shelter in our system.

Higher condition and opportunistic diurnal feeding of white grunts on HG artificial reefs may have important implications for nutrient and energy cycling in these systems. Foraging migrations undergone by grunts may be critical in translocating nutrients from the surrounding landscape to areas around reefs. Specifically, consumer-driven nutrient cycling (via excretion and egestion) has been shown to enhance productivity of corals (Meyer et al. 1983) and seagrass adjacent to reefs (Allgeier et al. 2013). Additionally, reefs with more seagrass surrounding them often support higher densities and increased production of fishes, especially grunts (Grober-Dunsmore et al. 2009, Yeager et al. 2011, 2012). Furthermore, the scale of the response in seagrass growth around artificial reefs has been found to be positively related to fish densities (Layman et al. 2013). If larger schools of grunts on artificial reefs have access to increased foraging resources (perhaps by making more opportunistic foraging bouts during the day in adjacent seagrass habitat), they may further benefit from increased local productivity. In turn, the increased activity and density of grunts on these reefs may lead to increased excretion rates, resulting in a positive feedback between grunt density and local primary productivity.

While we did not find a strong effect of landscape context on density-dependent condition for grunts in this study, this does not mean the landscape context is unimportant for the regulation and productivity of fish populations. First, while seagrass availability within the landscape did vary among our landscape treatments, it was still moderate throughout most of the study area. Whether grunts in areas with lower seagrass cover suffer reduced condition is unknown. Furthermore, the cover of seagrass within the landscape (within $100 \mathrm{~m}$ of the reef) has previously been found to be positively related to white grunt abundance on artificial reefs (Yeager et al. 2012). If landscape degradation (i.e., loss in seagrass cover) leads to decreased conspecific densities, this could also negatively impact fish condition. Therefore, by positively affecting conspecific densities, higher seagrass cover in the landscape may still result in higher measures of individual performance.

In this study, we focused on density-dependent responses in fish condition as a metric of individual performance, most likely related to differences in foraging potential. However, conspecific density and landscape context may have different effects on alternate components of fitness. In addition to mediating food 
availability for white grunts, differences in structural complexity between seagrass beds of varying cover and unvegetated habitat may also result in differences in risk for grunts. Much work on reef fishes has shown that shelter availability within the landscape (although often limited to the reef itself) may be an important mediator of density-dependent mortality for reef species (Hixon and Webster 2002). Specifically, increasing competition for suitable shelter may increase predation risk for individuals as densities increase, and should decrease in landscapes with more refuges (Hixon and Beets 1993, Forrester and Steele 2004). Increased shelter availability within the foraging habitat or differences in predator encounter rates across landscape types could directly impact mortality in white grunts. However, if shelter is not limiting in the landscape, larger group sizes should reduce mortality risk, especially for group-living species. In fact, a recent review by White et al. (2010) reports that mortality is more likely to display inverse density dependence in group-living species of reef fishes when compared to solitary species, especially at localized scales.

The most common form of inverse density dependence recognized by fisheries managers relates to decompensation, i.e., depressed population growth rate at low population densities, or a demographic form of the Allee effect (Myers et al. 1995, Courchamp et al. 1999, Stephens et al. 1999). Herein, we provide another example of inverse density dependence that is manifest at population densities that are not extremely low, and relates to effects on a specific component of fitness. These results indicate that the direct negative effects of over-harvest on fish populations may be further compounded, specifically when reduced densities lead to declines in individual condition. Our study provides another example of how over-harvest leads to a degradation of population regulating mechanisms in fisheries species and the importance of understanding these mechanisms to promote effective management of coastal fisheries.

\section{ACKNOWLEDGMENTS}

We thank R. Abby-Lee, S. Archer, E. Henderson, T. Higgs, J. Peters, L. Pierre, S. Sebilian, K. Weisenborn, and M. Yeager for their assistance with field work. We thank Friends of the Environment for their logistical support and the Department of Marine Resources of The Bahamas for research permits. This projected was funded by a NSF Graduate Research Fellowship and a FIU Dissertation Year Fellowship to L. A. Yeager, an EPA Star Fellowship to E. W. Stoner, and a NSF OCE \#0746164 to C. A. Layman.

\section{Literature Cited}

Allgeier, J. E., L. A. Yeager, and C. A. Layman. 2013. Consumers regulate nutrient limitation regimes and primary production in seagrass ecosystems. Ecology 94:521-529.

Anderson, C. N. K., C. H. Hsieh, S. A. Sandin, R. Hewitt, A. Hollowed, J. Beddington, R. M. May, and G. Sugihara. 2008. Why fishing magnifies fluctuations in fish abundance. Nature 452:835-839.

Appeldoorn, R. S., A. Aguilar-Perera, B. L. K. Bouwmeester, G. D. Dennis, R. L. Hill, W. Merten, C. W. Recksiek, and
S. J. Williams. 2009. Movement of fishes (grunts: Haemulidae) across the coral reef seascape: a review of scales, patterns and processes. Caribbean Journal of Science 45:304316.

Appeldoorn, R. S., and K. C. Lindeman. 1985. Multispecies assessment in coral reef fisheries using higher taxonomic categories as unit stocks with an analysis of an artisanal haemulid fishery. Proceedings of the Fifth International Coral Reef Congress 5:507-514.

Appeldoorn, R. S., C. W. Recksiek, R. L. Hill, F. E. Pagan, and G. D. Dennis. 1997. Marine protected areas and reef fish movements: the role of habitat in controlling ontogenetic migration. Proceedings of the 8th International Coral Reef Symposium 2:1917-1922.

Bligh, E., and W. Dyer. 1959. A rapid method of total lipid extraction and purification. Canadian Journal of Biochemistry and Physiology 37:911-917.

Burke, N. C. 1995. Nocturnal foraging habitats of French and bluestriped grunts, Haemulon flavolineatum and $H$. sciurus, at Tobacco Caye, Belize. Environmental Biology of Fishes 42:365-374.

Caraco, T., S. Martindale, and H. R. Pulliam. 1980. Avian flocking in the presence of a predator. Nature 285:400-401.

Chalfoun, A. D., F. R. Thompson, and M. J. Ratnaswamy. 2002. Nest predators and fragmentation: a review and metaanalysis. Conservation Biology 16:306-318.

Clark, R. D., S. Pittman, C. Caldow, J. Christensen, B. Roque, R. S. Appeldoorn, and M. E. Monaco. 2009. Nocturnal fish movement and trophic flow across habitat boundaries in a coral reef ecosystem (SW Puerto Rico). Caribbean Journal of Science 45:282-303.

Courchamp, F., T. Clutton-Brock, and B. Grenfell. 1999. Inverse density dependence and the Allee effect. Trends in Ecology and Evolution 14:405-410.

Erickson, M. C. 1993. Lipid extraction from channel catfish muscle: comparison of solvent systems. Journal of Food Science 58:84-89.

Finstad, A. G., S. Einum, O. Ugedal, and T. Forseth. 2009. Spatial distribution of limited resources and local density regulation in juvenile Atlantic salmon. Journal of Animal Ecology 78:226-235.

Forrester, G. E., and M. A. Steele. 2004. Predators, prey refuges, and the spatial scaling of density-dependent prey mortality. Ecology 85:1332-1342.

Fretwell, S. D., and H. L. Lucas. 1970. On territorial behaviour and other factors influencing habitat distribtution in birds. Acta Biotheroretica 19:16-36.

Grober-Dunsmore, R., T. K. Frazer, J. P. Beets, W. J. Lindberg, P. Zwick, and N. A. Funicelli. 2008. Influence of landscape structure on reef fish assemblages. Landscape Ecology 23:37-53.

Grober-Dunsmore, R., S. J. Pittman, C. Caldow, M. S. Kendall, and T. K. Frazer. 2009. A landscape ecology approach for the study of ecological connectivity across tropical marine seascapes. Pages 493-530 in I. Nagelkerken, editor. Ecological connectivity among tropical coastal ecosystems. Springer, New York, New York, USA.

Hanski, I. 1990. Density dependence, regulation and variability in animal populations. Philosophical Transactions of the Royal Society B 330:141-150.

Helfman, G. S., J. L. Meyer, and W. N. McFarland. 1982. The ontogeny of twilight migration patterns in grunts (Pisces, Haemulidae). Animal Behaviour 30:317-326.

Hixon, M. A., and J. P. Beets. 1993. Predation, prey refuges, and the structure of coral-reef fish assemblages. Ecological Monographs 63:77-101.

Hixon, M. A., S. W. Pacala, and S. A. Sandin. 2002. Population regulation: historical context and contemporary challenges of open vs. closed systems. Ecology 83:1490-1508.

Hixon, M. A., and M. S. Webster. 2002. Density dependence in marine fishes: coral reefs populations as model systems. 
Pages 303-335 in P. Sale, editor. Coral reef fishes: dynamics and diversity in a complex ecosystem. Elsevier, Burlington, Massachusetts, USA.

Hovel, K. A., and R. N. Lipcius. 2001. Habitat fragmentation in a seagrass landscape: patch size and complexity control blue crab survival. Ecology 82:1814-1829.

Irlandi, E. A., W. G. Ambrose, and B. A. Orlando. 1995. Landscape ecology and the marine environment: how spatial configuration of seagrass habitat influences growth and survival of the bay scallop. Oikos 72:307-313.

Johnson, D. W. 2008. Combined effects of condition and density on post-settlement survival and growth of a marine fish. Oecologia 155:43-52.

Layman, C. A., J. E. Allgeier, L. A. Yeager, and E. W. Stoner. 2013. Thresholds of ecosystem response to nutrient enrichment from fish aggregations. Ecology 94:530-536.

Lorenzen, K., and K. Enberg. 2002. Density-dependent growth as a key mechanism in the regulation of fish populations: evidence from among-population comparisons. Proceedings of the Royal Society B 269:49-54.

Magurran, A. E., and T. J. Pitcher. 1983. Foraging, timidity and shoal size in minnows and goldfish. Behavioral Ecology and Sociobiology 12:147-152.

McFarland, W. N., and Z. M. Hillis. 1982. Observations on agonistic behavior between members of juvenile French and white grunts - family Haemulidae. Bulletin of Marine Science $32: 255-268$

Meyer, J. L., E. T. Schultz, and G. S. Helfman. 1983. Fish schools: an assist to corals. Science 220:1047-1049.

Murdoch, W. W. 1994. Population regulation in theory and practice. Ecology 75:271-287.

Myers, R., N. Barrowman, J. Hutchings, and A. Rosenberg. 1995. Population dynamics of exploited fish stocks at low population levels. Science 1106-1106.

Ogden, J. C., and P. R. Ehrlich. 1977. The behavior of heterotypic resting schools of juvenile grunts (Pomadasyidae). Marine Biology 42:273-280.

Ogden, J. C., and J. C. Zieman. 1977. Ecological aspects of coral reef-seagrass beds contacts in the Caribbean. Pages 377-382 in D. L. Taylor, editor. Proceedings of Third International Coral Reef Symposium volume 1: biology. Rosenstiel School of Marine and Atmospheric Science, Miami, Florida, USA.

Okamura, B. 1986. Group living and the effects of spatial position in aggregation of Mytilus edulis. Oecologia 69:341347.

Persson, L. 1983. Food consumption and competition between age classes in a perch Perca fluviatilis population in a shallow eutrophic lake. Oikos 40:197-207.

Pitcher, T. J., A. E. Magurran, and I. J. Winfield. 1982. Fish in larger schools find food faster. Behavioral Ecology and Sociobiology 10:149-151.

Polis, G. A., W. B. Anderson, and R. D. Holt. 1997. Toward an integration of landscape and food web ecology: the dynamics of spatially subsidized food webs. Annual Review of Ecology and Systematics 28:289-316.

Post, J. R., and E. A. Parkinson. 2001. Energy allocation strategy in young fish: allometry and survival. Ecology 82:1040-1051.

Power, M. E. 1992. Habitat heterogeneity and the functional significance of fish in river food webs. Ecology 73:1675-1688.
Pulliam, H. R., and T. Caraco. 1984. Living in groups: Is there an optimal group size? Pages 122-147 in J. R. Krebs and N. B. Davies, editors. Behavioural ecology: an evolutionary approach. Blackwell Scientific Publishing, Oxford, UK.

Randall, J. E. 1963. An analysis of the fish populations of artificial and natural reefs in the Virgin Islands. Caribbean Journal of Science 3:31-47.

Rose, K. A., J. H. Cowan, Jr., K. O. Winemiller, R. A. Myers, and R. Hilborn. 2001. Compensatory density dependence in fish populations: importance, controversy, understanding and prognosis. Fish and Fisheries 2:293-327.

SAS Institute. 2012. SAS software version 9.3. SAS Institute, Cary, North Carolina, USA.

Schmitt, E. F., R. D. Sluka, and K. M. Sullivan-Sealey. 2002. Evaluating the use of roving diver and transect surveys to assess the coral reef fish assemblage off southeastern Hispaniola. Coral Reefs 21:216-223.

Stephens, P. A., W. J. Sutherland, and R. P. Freckleton. 1999. What is the Allee effect? Oikos 87:185-190.

Teichert, M. A. K., S. Einum, A. G. Finstad, O. Ugedal, and T. Forseth. 2013. Ontogenetic timing of density dependence: location-specific patterns reflect distribution of a limiting resource. Population Ecology 55:575-583.

Verweij, M. C., I. Nagelkerken, S. L. J. Wartenbergh, I. R. Pen, and G. van der Velde. 2006. Caribbean mangroves and seagrass beds as daytime feeding habitats for juvenile French grunts, Haemulon flavolineatum. Marine Biology 149:12911299.

Vickery, J. A., J. R. Tallowin, R. E. Feber, E. J. Asteraki, P. W. Atkinson, R. J. Fuller, and V. K. Brown. 2001. The management of lowland neutral grasslands in Britain: effects of agricultural practices on birds and their food resources. Journal of Applied Ecology 38:647-664.

Wang, G. M., N. T. Hobbs, R. B. Boone, A. W. Illius, I. J. Gordon, J. E. Gross, and K. L. Hamlin. 2006. Spatial and temporal variability modify density dependence in populations of large herbivores. Ecology 87:95-102.

White, J. W., J. F. Samhouri, A. C. Stier, C. L. Wormald, S. L. Hamilton, and S. A. Sandin. 2010. Synthesizing mechanisms of density dependence in reef fishes: behavior, habitat configuration, and observational scale. Ecology 91:19491961.

White, J. W., and R. R. Warner. 2007. Behavioral and energetic costs of group membership in a coral reef fish. Oecologia 154:423-433.

Wormald, C. L., M. A. Steele, and G. E. Forrester. 2012. High population density enhances recruitment and survival of a harvested coral reef fish. Ecological Applications 23:365-373.

Yeager, L. A., C. L. Acevedo, and C. A. Layman. 2012. Effects of seascape context on condition, abundance, and secondary production of a coral reef fish, Haemulon plumierii. Marine Ecology Progress Series 462:231-240.

Yeager, L. A., C. A. Layman, and J. E. Allgeier. 2011. Effects of habitat heterogeneity at multiple spatial scales on fish community assembly. Oecologia 167:157-168.

Zapata, M. J. 2013. Diel variation in fish community structure on natural and artificial patch reefs. Undergraduate Honors Thesis. Florida International University, Miami, Florida, USA. 